\title{
DEVELOPMENT OF DIALECTICAL THINKING IN STUDENTS AS A FACTOR IN IMPROVING THE QUALITY OF HIGHER EDUCATION IN TECHNICAL UNIVERSITIES
}

\author{
Elena Nikolayevna Rashchikulina Natalya Aleksandrovna Plugina* Lyudmila Petrovna Panova \\ Elena Nikolaevna Kondrashova Tatyana Aleksandrovna Bezenkova Olga Sergeevna Mameteva \\ Nosov Magnitogorsk State Technical University, Russian Federation
}

The issue of improving the higher education quality within the framework of gnostic approach is updated in the article against the backdrop of dynamic scientific and technical process development and globalization of economic and social development. The purpose of the article is to develop a structural and logical approach to ensuring dialectical thinking development in students using integrative approach and complementarity method in the process of instruction. A low level of dialectical thinking in students has been revealed as a result of a pedagogical experiment in higher educational institutions of the Russian Federation. Principles, criteria and conditions for improving methodological support have been developed and substantiated through the example of such academic disciplines as 'Modern Natural Science Concept' and 'General Physics' with the aim to provide cross-curriculum communications and to form integrative concepts. A system of criteria for integrative concepts formedness in students has been reasoned with the use of special exercises of interdisciplinary reflexive supplementary type in the process of instruction. A problem-based developmental programmed exercise aimed at development of dialectical thinking in terms of the above academic disciplines has been elaborated using the complementarity method. Criteria for dialectical thinking development in students have been substantiated. The effectiveness of implementation of the proposed recommendations for the integrative method and the complementarity method application in higher education has been assessed.

Key words: Integrative Method, Complementarity Method, Dialectical Thinking in Students, Cross-Curriculum Communications, Integrative Concepts, Integrity, Re-development

\section{INTRODUCTION}

The main productive power is a man who creates national product and determines the pace of social development. The educational background and intellectual potential of a man determine the quality and productivity of labor. According to a dependence formulated by A. Maddison, an increase in the education appropriations by $1 \%$ leads to an increase in the country's gross domestic product (GDP) by $0.35 \%$ [01]. According to the Organization for Economic Cooperation and Development, if the average study period of a country's population is extended by one year, it raises GDP by 3-6\% [02]. The higher the proportion of population with a sound academic background (at least equal to complete secondary education) is in a country, the lower the level of socioeconomic differentiation is. Thus, education, especially higher education, exerts direct influence on social and economic development of society. Moreover, continuous industrial development and dynamic scientific and technological progress, intensification of globalization processes of economic and social development in the world necessitate access to quality higher education, that is, formation of labor skills writ large in students in the context of academic courses multidimensionality and variability in higher educational institutions. Consequently, a need to develop methodological approaches to improving the quality of continuous higher education using the integrative method and the complementarity method arises from the above. A comprehensive use of the integrative method and the complementarity method would create a basis for concept integrity as an optimality factor in the content of education and in development of dialectical thinking in students. It is this approach that creates a synergistic effect of integrity with reference to a student personality, to exhaustibility in terms of academic content and elementality as an indispensable condition of completeness and integrity. In turn, this would ensure effective implementation of gnostic approach in education as a factor in enhancing intellectualization of modern production, on the one hand, and ensuring a high standard of knowledge as a component in human potential, on the other hand.

\section{LITERATURE REVIEW}

In the $18^{\text {th }}-19^{\text {th }}$ centuries, scholars focused primarily on socio-political functions of higher education: reducing crime rates and dissolute lifestyle, addressing class conflicts, increasing social mobility [03], V. Petty [04]. However, with the development of capitalist production that contributed to the growth in generation of capital and inequality in the process of its distribution, the need to determine factors of economic and social development of society became actual. Pursuant thereto, theories on quality of knowledge as a factor in technological progress and economic productivity of economy were devel-

\footnotetext{
* Nosov Magnitogorsk State Technical University, Lenin Street, 38, Magnitogorsk city, Chelyabinsk Region, Russian Federation, natalieplugina@yandex.ru
} 
oped (Edward Denison, Robert Barro, A. Marshall) [05]. In the $19^{\text {th }}-21^{\text {st }}$ century, the 'human capital' theory was conceived to be reflecting the significance of higher education expenditures and its quality improvement in economic terms (J.M. Keynes, S. Strumilina) [06]. Those scientific findings triggered active research in education aimed at improving the quality of higher education in order to match the trends of economic and social development of society.

Modern concepts in the education science development are premised on formation of gnostic skills in higher school [07-09] where they are basic with regard to other skills $[10,11]$. Within the framework of the gnostic approach, the integrative approach has begun to be considered as an actual need of modern higher education and as a basis for dialectical thinking in educational process. Natural science disciplines were considered, including physics, mathematics and computer science, from the point of view of their interconnection based on cross-curriculum communications [12]. The integrative approach was the mainstay of teaching cognate disciplines combining two or more subjects and their content; it served as an instructional time saver and ensured best possible acquisition of academic subject matters by integrating concepts as a factor in improving the quality of education [13].

In the context of inexhaustible informational and structurally organizational sources of instruction capable of meeting the requirements of a wide variety of educational models, complementarity theories in the process of instruction in higher school are being developed. Initial$\mathrm{ly}$, the idea of using the complementarity principle by $\mathrm{N}$. Bohr [14] as a method of interdisciplinary research and its use in education science belongs to V.A. Semenov [15]. A.V. Mudrik [16], within the framework of social education, assessed the productivity of the complementarity principle as a general scientific methodological tool in pedagogy. Justifying the inexpediency of one dominant, scholars have been developing the idea of a unity of both conventional and problem-based teaching methods in higher education providing teaching staff and determining the place of problem-based and conventional teaching on a case-by-case basis $[17,18]$.

Despite a sufficient degree of fundamental development of the problems of higher education quality improvement, the variability of academic disciplines and bachelor's courses in higher education institutions necessitates development of methodological approaches to ensuring integration of concepts in each specific case. Only such an approach would ensure an increase in the effectiveness of methodological support for academic disciplines and educational process with the aim of developing dialectical thinking in students as a factor in transforming the linear and one-dimensional worldview of university students into a lateral and multidimensional worldview and as an indication of a new scientific paradigm in pedagogy.
The goal of the research was to develop a structural and logical approach to integration of the conceptual framework based on the integrative approach and the complementarity method through the example of academic disciplines 'Modern Natural Science Concept' and 'General Physics' in the bachelor-level program 'Applied Mathematics and Informatics' in Russian universities.

In the course of the research, the following tasks of scientific inquiry were set:

- reasoning of the need for intensive higher education development in the Russian Federation as a factor in the country's economic and social development;

- evaluation of dialectical thinking development in university students in the context of conventional learning process organization;

- elaboration of operational recommendations for methodological support and organization of instruction based on the integrative method and the complementarity method for disciplines 'Modern Natural Science Concept' and 'General Physics';

- evaluation of effectiveness of the use of integrative concepts within the framework of the cross-curriculum intercommunication of disciplines 'Modern Natural Science Concept' and 'General Physics' for development of dialectical thinking in students.

\section{MATERIALS AND METHODS}

To achieve the primary goal of research and to prove the scientific hypotheses made, the following methods of scientific cognition were used as the methodological basis.

The method of theoretical generalization was used to justify the need to improve the quality of higher education in the Russian Federation as a factor in economic and social development.

The method of complementarity and integrative method was used to elaborate practical recommendations for methodological support and organization of instruction with the aim of developing dialectical thinking in students by forming integrative concepts.

The graphical method was used for visual representation of statistical material and a schematic representation of the basic theoretical framework for the study.

The method of pedagogical experiment was used to evaluate the effectiveness of the integrative method and the method of complementarity in the educational process for development of dialectical thinking in students.

A pedagogical experiment is a purposeful systematic reproduction of the educational process elements and its evaluation on the basis of a prefabricated plan [19]. The advantage of pedagogical experiment over other methods of scientific research is that it helps to establish the nature of links between various components of the educational process, between factors, conditions and the results of a particular quality formation, to test hypotheses aimed at resolving contradictions that emerge in teaching and educational process. 
To establish the relationship between the level of education advancement and the level of economic development in the country, a correlation ratio is calculated [20]:

$$
r_{x y}=\frac{\sum_{i=1}^{m}\left(x_{i}-\bar{x}\right)\left(y_{i}-\bar{y}\right)}{\sqrt{\sum_{i=1}^{m}\left(x_{i}-\bar{x}\right)^{2} \cdot \sum_{i=1}^{m}\left(y_{i}-\bar{y}\right)^{2}}}
$$

where $x_{i}$ is the figure of the population's academic background level during the $i$-th period;

$y_{i}$ is the figure of the GDP level per capita during the i-th period;

$\bar{x}, \bar{y}$ are the average value of indicators of the population's academic background level and the GDP level per capita, respectively, for the period under study ;

$m$ is the number of periods.

The correlation ratio is measured in the range $[-1 ;+1]$. The correlation ratio value $<0$ indicates the inverse nature of communication, whereas the correlation ratio value $>0$ indicates the direct one.

To evaluate the strength of relationship in qualitative terms, the Chaddock scale was applied, whereby the value of the correlation ratio $|0.1|-|0.3|$ corresponds to a weak relationship strength; $|0.3|-|0.5|$ - moderate; $|0.5|-$ $|0.7|$ - notable; $|0.7|-|0.9|$ - high (strong); $|0.9|-|1|$ - very high [20].

The degree of return from quantitative and qualitative indicators of the higher education system development is determined through elasticity coefficients of the production function [21]:

$$
Y=X_{1}^{\alpha} \cdot X_{2}^{\beta}
$$

where $Y$ is GDP per capita;

$X_{1}$ is level of population coverage by higher education;

$X_{2}$ is the quality (literacy) grade of specialists;

$\alpha, \beta$ are elasticity coefficients for factors and , respectively.

To assess the sufficiency of a pedagogical experiment sample, the following formula is used [22]:

$$
S S=\frac{Z(\alpha)^{2} \cdot p \cdot(1-p)}{\varepsilon^{2}}
$$

where $S S$ is the sample size;

$Z(\alpha)$ is the standard deviation defined according to the selected confidence level (determined from the data in Table 1);

$\alpha$ is the probability belief;

$p$ is the sample variation;

$\varepsilon$ is the acceptable error level.

The effectiveness of the proposed methodology for development of dialectical thinking and formation of integrative concepts in students is determined by the following equations [23]:

$$
\eta_{e}=\frac{c_{n}}{c_{1}}
$$

where $\eta_{e}$ is the coefficient of information acquisition efficiency;

$C_{1}$ is the coefficient of thoroughness and depth of mastering information by students following the results of the first assessment;

$C_{n}$ is the coefficient of thoroughness and depth of mastering information by students following the results of the $i$-th assessment.

$$
\alpha=\frac{C_{e}}{C_{k}}
$$

where $C_{e}$ is the efficiency coefficient of acquisition in the experimental group;

$C_{k}$ is the efficiency coefficient of acquisition in the control group.

Statistically, the experimental results are confirmed by the criterion $\chi^{2}$. Pursuant to the results of the proposed methodology applied to develop dialectical thinking and to form integrative concepts in students, a test was administered, its results being subsequently formalized in Table 2 [24].

In Table $2 O_{i i}$ is the number of objects (returns based on the test results) in the $i$-th sample that fall into the $j$-th category based on the condition of a property under study;

$i=1,2$ is the number of samples (sample 1 is experimental, sample 2 is control);

$j=1,2$ is the number of categories (category 1 is correctly performed test, category 2 is incorrectly performed test);

$N=n 1+n 2$ is the total number of observation objects.

Pearson's $\chi^{2}$ is calculated by the formula [24]:

$$
\chi_{\text {est }}^{2}=\frac{N \cdot\left(\left|O_{11} \cdot O_{22}-O_{12} \cdot O_{21}\right|-\frac{N}{2}\right)^{2}}{n_{1} \cdot n_{2} \cdot\left(O_{11}+O_{21}\right) \cdot\left(O_{12}+O_{22}\right)}
$$

When $\chi_{\text {est }}^{2}>\chi_{\text {tab }}^{2}$ the null hypothesis of indistinction between the sample characteristics values is rejected, while at $\chi^{2}{ }_{\text {est }}>\chi^{2}$ tab it is accepted with a specified probability.

\section{RESULT}

\section{QUALITY OF HIGHER EDUCATION AS A FACTOR IN ECONOMIC AND SOCIAL DEVELOPMENT}

In the Russian Federation, the academic background level of population is ever-increasing. The academic background level indicator consists of a quantitative component (the level of population coverage by education) that describes the prevalence of education in the country and qualitative (adult literacy rate). During the period under study, the level of coverage of Russian citizens by education increased by $62.5 \%$ to reach $74.3 \%$ in 2017 . There is also an improvement in the quality of education. For 1990-2017, the literacy rate of the population increased by almost $4 \%$ to reach $97 \%$ in 2017 (Figure 1) [25]. 
Table 1: Values of normalized deviation

\begin{tabular}{|c|c|c|c|c|c|c|c|c|}
\hline $\begin{array}{c}\alpha, \\
\%\end{array}$ & 60 & 70 & 80 & 90 & 95 & 97 & 99 & 99,7 \\
\hline $\mathrm{Z}$ & 0.84 & 1.03 & 1.29 & 1.65 & 1.96 & 2.18 & 2.58 & 3.00 \\
\hline
\end{tabular}

Table 2: Test results

\begin{tabular}{|c|c|c|c|}
\hline & Category 1 & Category 2 & Number of objects in a sample \\
& & & \\
\hline Sample 1 & $O_{11}$ & $O_{12}$ & $O_{11}+O_{12}$ \\
\hline Sample 2 & $O_{21}$ & $O_{22}$ & $O_{21}+O_{22}$ \\
\hline Number of objects by category & $O_{11}+O_{21}$ & $O_{12}+O_{22}$ & $n_{1}+n_{2}=N$ \\
\hline
\end{tabular}

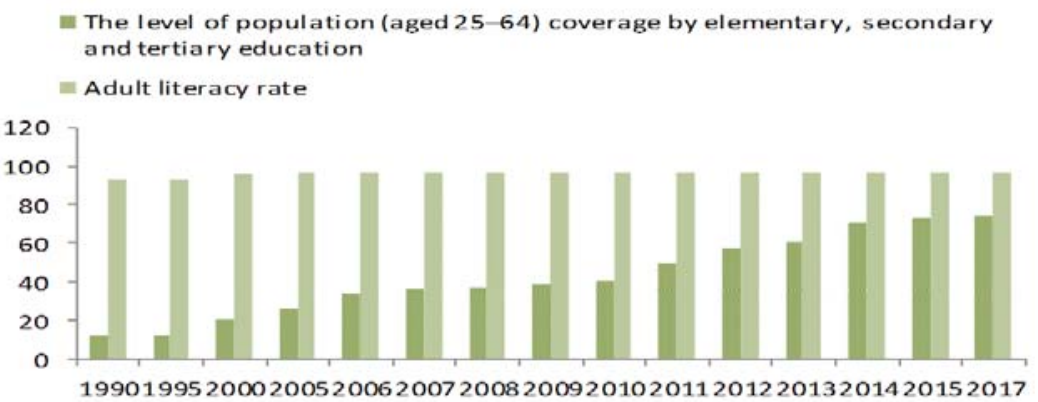

Figure 1: Dynamics of the indicators of the academic background level of the population in the Russian Federation, \%

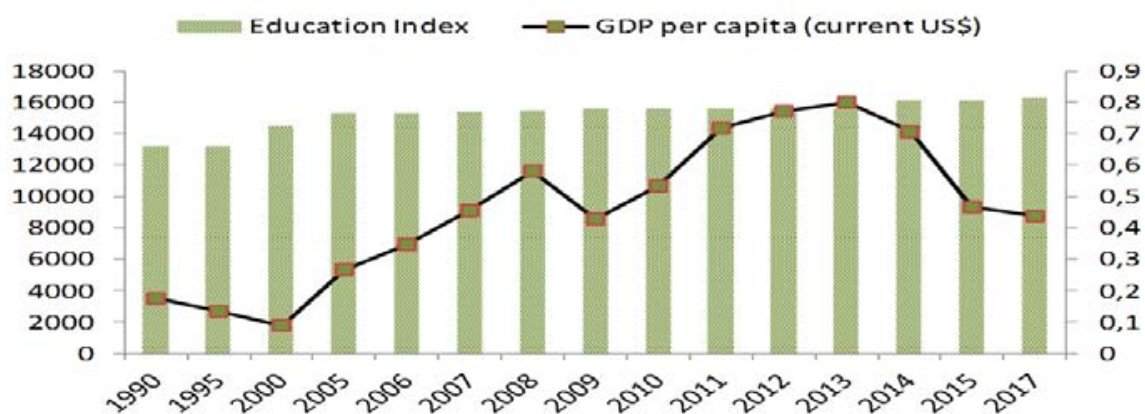

Figure 2: Dynamics of the academic background level of the population and GDP per capita in the Russian Federation

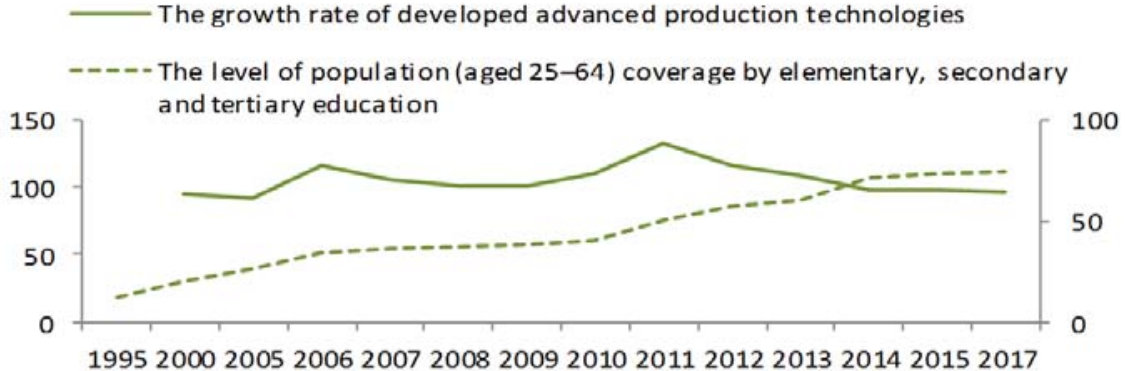

Figure 3: Development trend in the academic background level of the population and innovative potential in Russia, \% 
A generalized indicator of education development in the country is educational background index based on the adult literacy rate index (aged 15 and older) and coverage by elementary, secondary and tertiary education. The indicator is measured in the range $[0 ; 1]$ based on the weighted average values of these particular indicators [26].

In 1990-2017 the educational background index value in the Russian Federation grew from 0.66 to 0.82 , which indicates an increase in the academic background level of population (Figure 2). Despite the positive dynamics, the indicator value remains at a low level since the indicator level for developed countries should be 0.8-0.9 [26].

It should be noted that the positive dynamics of the academic background level of population is accompanied by increasing levels of GDP per capita in Russia (Figure 2) [27]. The value of the correlation ratio calculated by equation 1 was 0.71 , which is identified on the Chaddock scale as a strong direct correlation [20]. However, despite the growth of the country's educational potential, the return of college-educated professionals has declined. This is evidenced by a downward trend in the growth rate of the state's innovative potential, which updates the need to address the problem of education quality improvement in the Russian Federation (Figure 3) [28].

International practices show a varying degree of return from the higher education system with a different combination of the number of professionals and the higher education quality. With an invariable number of professionals but with an increase in the quality of education, the national income increases, this indicates the intensive way of the education system development. Conversely, with an invariable quality of education, an increase in the number of professionals entails an increase in the national income and is characterized by the extensive way of the higher education system development.

By constructing a derived function (Equation 2) between the level of GDP per capita in the Russian Federation for 1990-2017 and the number of college-educated professionals and their literacy rate, the elasticity coefficient values are calculated: $\alpha=0.25 ; \beta=0.57$, respectively (Equation 7).

$$
Y=X_{1}^{0.25} \cdot X_{2}^{0.57}
$$

Since $\alpha<\beta$, it is arguable that the return of the Russian education system is more sensitive to the quality of education than the number of professionals. Thus, with an increase in the level of coverage by higher education by $1 \%$, GDP per capita will increase by $0.25 \%$; with an increase in the quality of professionals by $1 \%$, GDP per capita will increase by $0.57 \%$. Hence, in present-day conditions the state must ensure an intensive way of development of the national higher education system in order to ensure sustainable economic and social development of the state.

Therefore, by 2010 the Russian Federation reformed its national education system consistent with the Bologna
Declaration and updated the federal state educational standards for higher education [29]. The main transformation was the gnostic approach constituted as the basis for a transformational change; it envisaged formation of competencies in terms of active efforts and professional activity in all of their aspects in students. Preference in university activities is given to investment in human capital assets. For this purpose, a system of motivations for students and teachers is created in the production of a high-quality modern educational product.

One of the main functions of the Russian higher education system is mass training of qualified specialists, transfer of professional knowledge, skills, expertise and standards within the framework of the gnostic approach. In modern context, this function is performed by the integrative method and the method of complementary instruction for students.

Integration is interconnectedness, a systemic connection into a coherent whole and, accordingly, the process of establishing such connections, convergence, and unification [30]. The principle of integration commits to transform educational activity in the system of higher educational institutions taking into account the synthesis and unification of educational areas, which involves obtaining a comprehensive educational product that ensures formation of integral qualities of a student's personality and their harmonious social engagement.

The main concept of the complementarity method in pedagogy and psychology is a generalized complementarity principle: 'in a system of properties of any object or subject, pairs of complementary and, in particular, opposing properties, features or traits, whose simultaneous and equally intense exhibition is impossible or unlikely, are in relative stable asymmetrical harmony' [31]. G.G. Granatov defines the psychological and pedagogical principle of complementarity as follows: 'in the thinking and character of any person, a pair of complementary or opposing properties, forms or qualities, whose simultaneous and equally intense exhibition is impossible or unlikely, are in relative stable asymmetrical harmony' [31]. That is why truly dialectical thinking unites supplementary aspects: ideological-conceptual, subjective-emotional and reflexive; it is only in this case when it can be identified as pedagogical thinking.

The use of complexity and systematicity when structuring the content of education, as well as the organization of instruction process in higher education on the basis of integration, makes it possible to formulate a system of integrative concepts as a recommended sequence of activities of a high level of generalization. In the context of multidimensionality of disciplines in the education sector, which are not mutually exclusive but rather complementary, integrative concepts form an lateral, dialectical, simultaneous and systemic thinking in students and promote development of a holistic perception of the world and involvement of various mechanisms of cognitive and research activity. In this regard, in the context of subject diversity, the problem of continuous support and devel- 
opment of a concept integration system in the process of teaching students in higher education institutions is updated.

\section{THE USE OF THE INTEGRATIVE METHOD AND THE COMPLEMENTARITY METHOD IN EDUCATIONAL PROCESS AS THE BASIS FOR DIALECTICAL THINKING DEVELOPMENT}

Taking into account the fact that the role of fundamental sciences in bachelor-level programs is increasing, such natural science courses as 'Modern Natural Science Concept' and the 'General Physics' have been designated as the target of research in order to ensure systematicity in educational process. These training courses are a part of the bachelor degree program 'Applied Mathematics and Informatics' [32].

Determination of these courses as a target of research is conditioned by the fact that 'Modern Natural Science Concept' is aimed at familiarization of students with the key concepts of various natural sciences (physics, chemistry, biology, etc.) in general cultural and historical terms. The course 'General Physics' is studied concurrently and is aimed at familiarizing students with fundamental principles of physics and possibilities of their application to address certain problems arising from further professional activities. In other words, these academic disciplines are designed to familiarize students with the physical world view, to study theoretical methods of analyzing physical phenomena, to acquire the skills of experimental research of physical phenomena and processes, and to develop students' basic natural scientific world outlook.

Analysis of the existing methodological support for the course 'Modern Natural Science Concept' and 'General Physics' has identified the following contradictions: between the creative nature of concept genesis in scientific knowledge and a palliative method of introducing 'ready' knowledge in teaching; between the integrating function of fundamental scientific concepts and inconsistent treatment of the same concepts in these disciplines.

In order to resolve these contradictions, a pedagogical experiment was conducted within the framework of the research that has made it possible to identify features of dialectical thinking development in students and specifics of integrative concepts formation in the process of studying the academic disciplines 'Modern Natural Science Concept' and 'General Physics', to determine the teaching performance in these disciplines in terms of cross-curriculum communications as a factor of knowledge complementarity.

The use of pedagogical experiment as a basic research approach is conditioned by the fact that the problem under investigation lies predominantly in the subjectivist plane, that is, at the level of its perception by an individual [19]. Pursuant thereto, a method based on judgmental evaluations of respondents was chosen as the research approach.
To achieve consistent experimental results, it is important to form a sampling frame by singling out from the target of research a totality that would be subject to study and would summarize properties of the general population, that is, be representative.

For a large general population ( $>30$ people), which is a student body of technological faculties in the Russian Federation, the sufficiency of a sampling frame for conducting sociological research is determined by Equation 3.

The acceptable confidence level (Table 1), whereby research findings are representative and statistically significant, is $90 \%(\alpha=90 \%)$, with confidence interval $\pm 5 \%$. On the basis thereof, the required sampling frame size totals 273 people. With this number of respondents, results of the pedagogical experiment will be representative.

The structural-functional model of the experiment is shown in Figure 4.

The experiment covered 511 students of all nations in the Nosov Magnitogorsk State Technical University (MSTU) majoring in technological (171 people), physicomathematical (170 people), and 'Pedagogy, Psychology and Social Work' training programs (170 people).

MSTU is one of the reputable comprehensive technical universities in Russia. The university is famous at the domestic and international level for its scientific schools, has a broad geographical spread of creative and scientific links with major Russian and foreign universities. About 15,000 students study at the university and its branch to major in 848 academic programs of higher education and in 20 specialties of secondary vocational education [33]. Since the university has a ramified educational structure and a large student body closely integrated into the domestic and international educational process, as well as high mobility, the results of the experiment conducted on the premises of the university can be considered representative of all Russian universities.

The experiment validity is also evidenced by the fact that the sampling frame size of the experiment exceeds the minimum required (273 people), with all nations and different areas of student training covered.

At the first stage, the stage of a trial pedagogical experiment aimed at formation of an operational hypothesis and research objectives, 511 first and second year students were asked to supply a response to 7 dichotomous questions of a worldview questionnaire (yes/no response options) regarding: 1) belief in God, 2) attitude to money, 3 ) existence of a moral ideal, 4) existence of their own thinking, 5) knowledge of the laws of straight sequential thought, 6) knowledge of the thinking pattern title, 7) knowledge of the title of the scientific view of Nature.

Pursuant to this stage, the following results were obtained. The number of faithful students was $98.8 \% ; 99.0 \%$ of them are aware that not everything can be bought with money; $85.5 \%$ have a moral ideal, according to the ques- 
tionnaire; only a small fraction of students know the laws of straight sequential thought $-28.2 \% ; 56.0 \%$ reflect on their own thinking; yet, $12.7 \%$ of them know that a thinking pattern has no title; conversely, $85.3 \%$ of them know the title of the scientific view of Nature.

These data indicate a highly developed system of students' moral values, a mythological and religious worldview but a low level of scientific knowledge, which indicates an insufficient level of quality retention of material in these disciplines. In this regard, there arises a need to form a comprehensive world outlook in university students based on increased level of scientific world cognition using the integrative method and the complementarity method in the process of instruction. The experimental results at the first stage confirm the adequacy and significance of the complementarity idea about six known thinking styles and all four main worldview types - mythological, religious, scientific- idealistic, and scientific-materialistic - actually merging in a living and functioning thinking of any individual [34, 35].

At the second stage of the experiment, a test was used to check the residual knowledge of students in natural science disciplines. The survey involved the same students as at the first stage. The residual knowledge was tested based on answers to questions concerning basic concepts in physics, mathematics, computer science, chemistry, ecology courses, such as 'light', 'matter', 'displacement flux', 'gravity', 'derivative', 'limit', 'probability', 'natural number', 'plane geometry', 'set', 'adapter', 'oper- ating system', 'file system', 'defragmentation', 'archiving', 'valence', 'isotope', 'atom', 'ecosystem', 'biosphere', 'phytocenosis', 'microbiocenosis', 'biomass', 'producer'.

As may be inferred from the results obtained, the level of residual knowledge of students $(C)$ in natural science disciplines is approximately identical, whilst low, for different training programs:

- $51 \%$ for technological programs $\left(\mathrm{C}_{\mathrm{T}}=0.51\right)$;

- $49 \%$ for physicomathematical programs $\left(\mathrm{C}_{\mathrm{PM}}=0.49\right)$;

- $41 \%$ for the program 'Pedagogy, Psychology and Social Work' $\left(\mathrm{C}_{\mathrm{pPsw}}=0.41\right)$.

However, the thinking level and style of each student can be estimated only tenuously based on these data. For a more objective assessment of students' thinking style and, therefore, choice of the most effective method for forming a system of scientific ideas in students, the authors administered tests on the following concepts of modern physical worldview: conservation and shortrange interaction [36]. Residual knowledge of the conservation law principles was tested by questions related to the 'energy', 'motion', 'statics', 'dynamics', 'kinetic energy,' 'potential energy,' 'force' concepts; kinetic and potential energy identification assignments; kinetic energy formulas for rotational and translational motion, the moment of inertia of a material particle, the potential energy of a body lifted above the Earth, the potential energy of bodies interacting through gravitational attraction, the potential energy of an elastically deformed body.

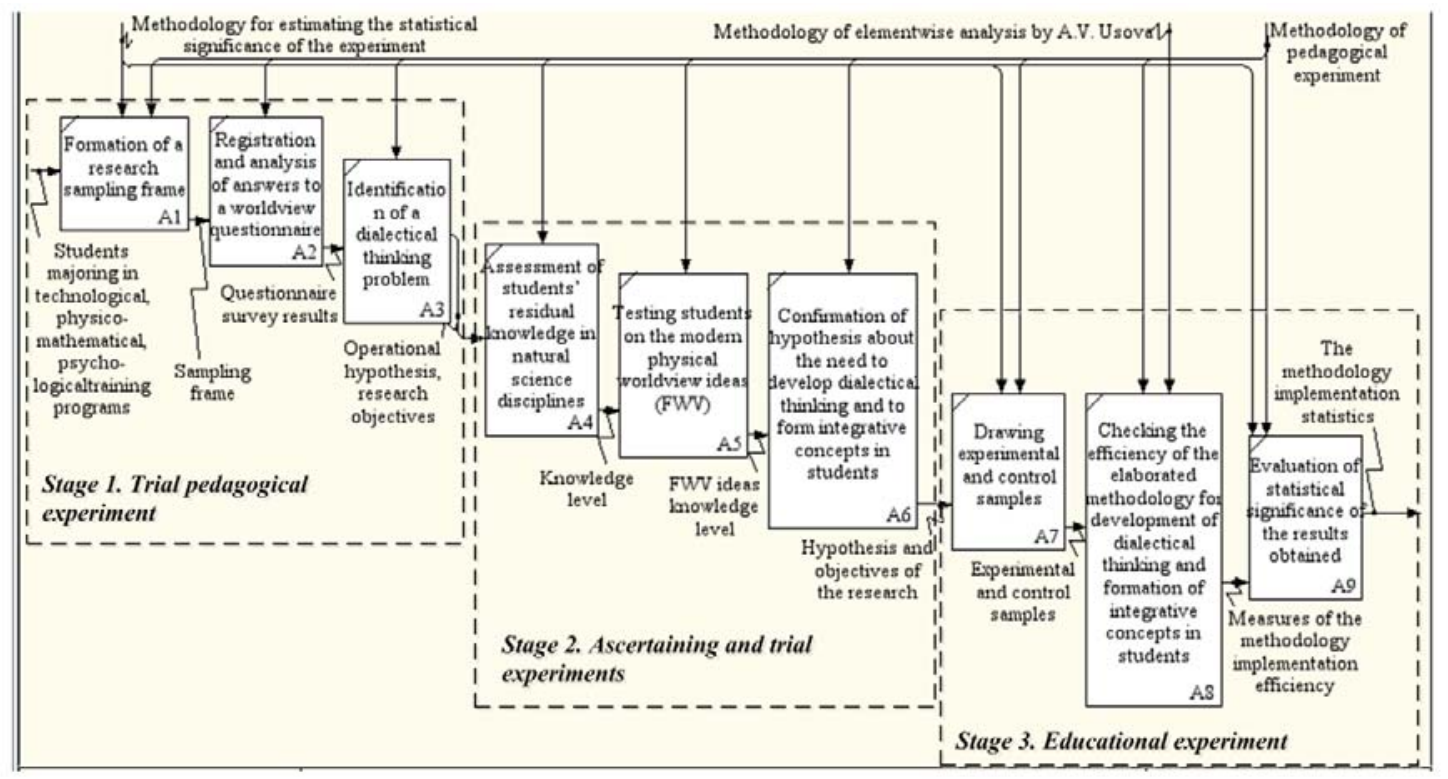

Figure 4: Structural-functional model of the pedagogical experiment for dialectical thinking development in students 
The short-range interaction testing encompassed questions on the essence of the 'physical field', 'electromagnetic interaction', 'gravitational interaction', 'gravitation waves', 'particle', 'matter', 'impulse', 'speed' concepts; Maxwell's electromagnetic theory, the laws of classical dynamic mechanics.

As a result, it has been established that the knowledge level of the physical worldview ideas (PWV) is as follows:

1. for the conservation concept: $C_{T}=0.65, C_{P M}=0.62$, $\mathrm{C}_{\mathrm{PPSW}}=0.57$;

2. for the short-range interaction concept: $C_{T}=0.37$, $C_{P M}=0.35, C_{P P S W}=0.22$.

The low level of knowledge in natural science disciplines and physical worldview concepts confirms the hypothesis of the need to form a comprehensive worldview in university students on the basis of dialectical thinking development and integrative concepts formation in students when teaching' Modern Natural Science Concept' and 'General Physics' courses.

In the process of elaborating methodological support for these training courses taking into account the pedagogical experimental results of the first stage, cross-curriculum communications became an indispensable prerequisite and were ensured by implementing the following principles [37]:

- the principle of eliminating duplication when studying the same problems in class;

- the principle of unity in the use of definitions when teaching theories and laws, for example, when students study the law of universal gravitation, the natural science worldview, the mechanical view of the universe, etc.;

- the principle of unambiguous interpretation of basic concepts, in particular, such categories as 'scientific worldview', 'light', 'complementarity' and so on.

- the principle of taking into consideration skills acquired in other academic disciplines;

- the principle of consistent approach to formation of generalized skills and expertise (cognitive and practical). Within the framework of the experiment, the generalized plan of A.V. Usova [38], as well as the aggregate approach to problem analysis developed by N.N. Tulkibayeva [39] were used;

- the principle of formation of a scientific worldview and a notion of an overall scientific worldview;

- the principle of philosophical concepts formation.

In the process of methodological support development for these disciplines, continuity (certain conformity with traditions or studies available) and novelty became important criteria for ensuring cross-curriculum communications. At the same time, it was taken into account that, under necessary conditions, continuity should prevail, whereas novelty should prevail under sufficient conditions. Thereby, the following factors were assigned to the necessary conditions:
- an increase in systematicity and ideological conceptuality in natural science disciplines (natural science and physics) teaching, in particular, through special academic training of students, including understanding and use by students of the categories 'concept' and 'idea';

- implementation of systematic cross-curriculum communications aimed at integration of narrow-subject knowledge.

The system of sufficient conditions is based on:

- natural and optimal introduction of the dialectical thinking' category and integrative concepts about the method of complementarity, the natural scientific worldview, light, etc. into the natural science syllabi;

- the use of special assignments and exercises of reflexive supplementary type aimed at knowledge of the essence of objects merging with self-knowledge [37].

Also, to improve the methodological support for the above disciplines, the following framework modalities were used:

- comparison of the PWV ideas with basic principles (explanation, simplicity, correspondence, conservation, observability) and characteristic features (discreteness, continuity, approximation, static and synthetical character) of the modern natural science thinking style;

- identification of those most fundamental of them, that is, those with the highest information capacity the largest number of communications with the rest, wherefrom the rest logically appear;

- identification of those defining basic properties of space, time and motion, complementing them with the modern models of space, time and the universe. Grouping in accordance with the development stages of PWV and CWV (chemical worldview);

- identification of those:

1.corresponding to the ideas of biological worldview (BWV);

2. contradicting basic BWV ideas (for example, of non-conservation, asymmetry, anti-entropicity, irreversibility) or able to be represented diadicly, in pairs -in complementary unity;

- supplementing them with laws of ecology as an integrative 'co-evolutionary' science.

- identification of those able to be used in formation of a subjective ecocentric type of 'ecological consciousness' of man of the $21^{\text {st }}$ century.

The second sufficient condition for ensuring cross-curriculum communications is directly aimed at developing integrative concepts and dialectical thinking in students with the help of special assignments and exercises of reflexive supplementary type. In the process of instruction, the following forms of the instruction process organization were used: a lecture; a problem-based seminar; 
business games; students' individual work in the form of assignments of reflexive supplementary type and analysis of supplementary literature by students. In addition, generalization and analysis of a complex of special exercises of cross-curriculum reflexive and supplementary type have allowed for the conclusion that criteria for integrative concepts formation in students should contribute to a fairly objective assessment of:

- the level of students mastering the complementarity method concept;

- the level of mastering the concept of light, the scientific worldview and other integrative concepts, hence, the level of dialectical thinking formedness;

- the ability to correctly assess or determine the actual and prospective styles of one's thinking;

- the ability to reflect (to think about the way one has thought and acted in the recent past, to think about the way one thinks, acts and controls their thoughts directly, to think about a plan for forthcoming actions);

- the ability to use, among other forms of evaluation, element wise analysis of the level of mastering concepts (including their own ones) [37].

According to the authors, it stands to reason that it is impossible to form such skills in terms of an isolated academic subject. All student courses should embrace a consistent approach, in particular, in the formation of scientific, much less integrative, 'cross-cutting' concepts. In this regard, the complementarity method developed in pedagogy and psychology by G.G. Granatov [31] has become the background for development of dialectical thinking in students in the disciplines 'Modern Natural Science Concept' and 'General Physics' along with the integrative method within the framework of the research.

Elaborating the above ideas in the current research, a problem-based developmental programmed exercise 'Evolution of the idea of complementarity' was developed for students to ensure the syllabi integrity in the process of instruction:

\section{What is the material essence of light?}

a) light is streams of matter particles emitted by luminous bodies;

b) light is a mechanical process, it is a mechanical wave in the elastic all-pervading 'world ether';

c) light is an electromagnetic wave in the 'world electromagnetic ether';

d) light is an electromagnetic field of optical radiation characterized by mass and defined in structure.

\section{What is the nature of light?}

a) it has a material, substantial nature since it is radiated and absorbed by matter and consists of the smallest particles of matter - light corpuscles;

b) light has a mechanical nature since it represents transmission of elastic impulses in the 'world ether'; c) light has a dual wave-corpuscule nature;

d) having a single electromagnetic nature, light has dual wave-corpuscule properties.

3. The dualism of light lies in the fact that:

a) there is some periodicity in the motion of light corpuscles associated with their own rotation exciting elastic etheric waves;

b) the elementary particles of an electromagnetic field (photons) it consists of take turns to exhibit their wave and corpuscular properties;

c) having a discrete, photonic structure and wave-like motion, it variously exhibits these contradictory properties under different conditions;

d) light behaves like a wave during propagation, while behaving like a stream of particles during radiation and absorption.

4. What is light (choose the correct definition)?:

a) light is a beam of rays emitted by luminous bodies;

b) light is an electromagnetic quantized field of optical radiation;

c) light is electromagnetic waves perceived by the human eye;

d) light is the field of any electromagnetic radiation, a photon gas.

5. In your opinion, what is the most common understanding of the idea of complementarity:

a) in the essence of light, its corpuscular and wave properties coexist in a harmonious unity mutually complementing each other but normally not exhibit simultaneously;

b) in thinking and in personality, pairs of opposing or complementary properties or traits are in a relatively stable and asymmetric harmony, their simultaneous and equally intense exhibition being impossible or unlikely;

c) in the system of properties of any object or subject, pairs of complementary and, in particular, opposing properties or qualities are in a relatively stable and asymmetric harmony, they coexist, their simultaneous and equally intense exhibition being impossible or unlikely;

d) as the saying goes, 'Extremes meet', 'Good and evil walk alongside' but, optimistically, with the hope for a better future, there is a conclusion: 'Every cloud has its silver lining,' 'It was a blessing in disguise'.

6. Which way to construe the idea of complementarity most explicitly conveys its genuine link with the idea of conservation:

a) in the process of social development, the class struggle persists and is continually exacerbated and embittered, so that there are hardly any periods when its intensity lessens - periods of harmonious complementarity of class interests, elimination of fundamental class contradictions; 
b) in the process of development of any objects, the unity and continuous 'struggle' of fundamentally opposite properties is always preserved, which is the source and the engine for development of nature, society and thinking;

c) it is not only the interaction of opposites, but also the tendency or aspiration of matter and consciousness to a relatively stable harmony of properties that is the source of development - a spiral rhythm of changes in these properties is also preserved in this development, but the rate of this change does not remain constant, it is continuously discrete: long-term, smooth and small (quantitative) changes in properties lead to frenetic, accelerated qualitative changes (leaps);

d) between the old (classical) and the new (revolutionary) knowledge, there is a continuum genetic affinity - a dialectical negation: the new is not in complete denial of the old, but rather contains the most rational part of it, complements it, transforms into it in a passage to the limit, clarifies the scope of its application.

7. Which complementarity in thinking terms appeals to you the most, which of them is 'to your liking'?

a) the conscious and subconscious, spirit and matter - that is, a spirit not too 'burdened' with matter and consciousness when 'twilight of consciousness' falls, times of enlightenment with flashes of insight and clairvoyance come - so-called 'twilight of the gods' (albeit the saying: 'Education is light, ignorance is darkness');

b) asymmetric harmony of the sensual, emotional and colorful - that is, its 'elation' and reasonable discipline of cognition, whereas the 'memory of heart' keeps dominating 'the lamenting memory of reason';

c) the content and the form with a reasonable unity of formal logical laws and general opposite thinking forms (analysis and synthesis, abstraction and concretization, deduction and induction);

d) practice and action first (without prior restriction of freedom), and then theory as a necessary combination of freedom and discipline (in particular, in the 'trial and error' method);

e) theory first (analysis of the situation with foresight, forecasting possible outcomes and assessing activity options), and then practice the pre-eminence of conscious discipline of thought over its freedom.

Each of the possible answers given in the first six paragraphs appeared as scientific (relative) truth at the time, but correct answers from the standpoint of modern science and from the standpoint of the requirements of the questions (points) themselves are the following: 1-d; 2-d; 3-c; 4-b; 5-c; 6-c. In the seventh question, you actually were to choose the desired and actual style that is characteristic of you (now dominant), or rather a thinking 'monostyle': 7-a - reasonable but cold, all-pervading; 7-b - one of the dialectical types, prevalently altruistic, giving 'warmth' and 'light' to other people; 7-c - formally logical, rational, punctual, but also prevalently 'cold'; $7-d$ - one of the empirical types; 7-e - theoretical. Yet, you are most likely characterized by a combination of two (for example, those you selected when reading this program for the first and second time) or even three thinking monostyles, and you are already able to accept and feel which ones. Assignments of psychological and pedagogical type for this programmed exercise will be given below (based on didactic considerations)

\section{Assignments for the problem-based developmental exercise}

1. If you performed this exercise in two stages (in two ways -with intuition prevalent over consciousness and vice versa), which of these ways proved to be more fruitful, more effective for yourself? Why? (Try to contemplate on possible reasons therefore for your own information).

2. In your opinion, did all the thinking properties emphasized above prove themselves while you were performing this task? How about those not emphasized? Did they 'work'?

3 . Is the correct definition of light in 4-b a form of concept definition through the nearest genus and generic differences?

4. Which understanding of the complementarity idea (from those given in paragraph 5) can be considered a form of defining the psychological and pedagogical principle of complementarity? (Answer: 5-b)

5. Which of the answers in this program can be considered a definition of the general scientific correspondence principle? (6-g)

6. In your opinion, which ones in the above pairs of properties dominated in your thinking when reading for the first time, and which ones - for the second time? Perhaps, during the second, more methodical reading, all the properties emphasized by the authors dominated?

7. Is it possible to consider the above-mentioned pair, binary representation of the thinking properties to be one of the forms of their definition?

8. Which ones in each pair of these properties reflect the first nature of human thinking to a greater extent (compatibility with to the 'nature of things', its naturalness - almost according to J. Dewey (52, p. 26) its spontaneity or 'freedom') - its natural conformity (83, pp. 99-100)? Maybe all those not emphasized?

9. As a reflection of the second nature of man, the culture of thinking (truly actualizing the 'link of times') is first and foremost indelible marks of their past experience imprinted in the subconscious (in the form of habits, morals, manners, habits, dominant thinking style, etc.) But the cultural congruence of thinking is a broader category (conscious-subconscious), whose forms are also conceptual or emotionally perceived concepts, ideas, beliefs, images or pictures, skills, etc. in the consciousness. Is it possible to say 
that all the thinking properties emphasized rather reflect its cultural congruence to a greater extent?

10. Have all the four steps (or blocks) mentioned above been implemented in performing this exercise to contribute to the development of your concepts of light and the complementarity principle? Where, in which paragraphs or response options (or in what part of this chapter) did you find the core - the 'moment of truth' in comprehending their essence?

\section{DISCUSSION}

Dialectical thinking does not only involve understanding the universality of connections or the realization that each concept is in a certain relationship and connection with other concepts, but also availability of professional skills to show the relationship dialectics of the subjects under study and dialectics of the cognition process itself. With reference thereto, the pedagogical experiment was implemented over a semester - the period of 'Modern Natural Science Concept' and 'General Physics' studies by students. After studying these disciplines within the framework of the experiment, criteria for 'transition' of students' thinking from one to another level of dialectical thinking developed in them have been substantiated in order to assess the efficiency of the proposed recommended practices implementation:

- a 'transition' corresponding to a transformation of formal knowledge into concepts, skills and expertise with an increase in their generalization, irreversibility (solidity), convolution, with awareness of phasing and a growth in systematicity;

- compliance with the four levels of development of the problem-solving ability in students [40];

- a change of the dominant element in the actual relatively stable asymmetric unity (complementarity) of 'freedom' and 'discipline' in the thinking of a student with their independence growing;

- a kind, level and type of pedagogical reflection and the development stage of the complementarity method concept (basis, core, consequence and general critical interpretation) associated with this level.

In setting up a correspondence between the coefficient values of thoroughness and depth of integrative concepts acquisition and the levels of dialectical thinking development, a scale by V.P. Bespalko [40] was used:

' 0 ' level: $\mathrm{C}<0.5$ (elementary empirical);

I level: $0.5<\mathrm{C} £ 0.7$;

(schoolish)

Il level: $0.7<\mathrm{C} £ 0.8$ (methodical)

III level: $0.8<\mathrm{C} £ 0.9$ (research)

IV level: $\quad 0.9<\mathrm{CE} 1.0$.

(instructive, methodological)
It is to be recalled that here $C$ is the coefficient of thoroughness and depth of mastering concepts and skills by students calculated by the method of elementwise analysis developed by A.V. Usova [38].

In many exercises, the authors conducted three assessments. Thus, for example, the programmed exercise (with a simplified program) improved by the authors 'Evolution of the ideas of light (and complementarity)' was performed by students three times. The elementwise analysis of the last assessment data showed that the development efficiency ratio (thoroughness of acquisition) of the light concept for the experimental group turned out to be rather high -0.99 . This has allowed for the conclusion that for most students, the idea of light (and complementarity) has transformed into a mature and systemic concept.

The acquisition efficiency ratio of the light concept content, when comparing the results of the third and first assessments calculated by Equation 4, turned out to be quite high: $\eta_{\mathrm{E}}=3.41$.

Despite the great importance of the acquisition efficiency ratio, according to these data, it is possible to estimate at what level of dialectical thinking development each student is and at what stage of acquisition of the idea and method of complementarity they eventually are only tenuously or not quite accurately.

Using the method of comparative evaluation by Equation 5 , the authors have calculated comparative efficiency ratios of the methodology used in the acquisition of the light concept:

$$
\begin{aligned}
& \alpha_{1}=\frac{0.29}{0.33}=0.88 \\
& \alpha_{3}=\frac{0.99}{0.65}=1.52,
\end{aligned}
$$$$
\alpha_{2}=\frac{0.70}{0.47}=1.49
$$

where $\alpha_{1}, \alpha_{2}, \alpha_{3}$ are comparative efficiency ratios based on the results of the first, second and third assessment, respectively.

Subsequent to the experimental results of the final stage, it can be said that the conventional organization of instruction in the form of lectures and practical sessions also contributes to the development of dialectical thinking in students to a certain extent since the efficiency ratio of acquisition of the light concept in the control group increases from 0.33 after the first assessment to 0.65 after the third one.

A detailed analysis has shown that the mastery level of the investigated concepts in the control group was significantly lower. This conclusion is also confirmed, in particular, by a comparison of the results of the programmed task 'Development of the idea of complementarity', compiled by the authors, that the students in those groups performed while studying the course 'Modern Natural Science Concepts' and the summary of the course 'General Physics'. Thus, the acquisition efficiency ratio of the idea (in the form of a principle and a method) of 
complementarity in the experimental group after the third assessment turned out to be $\operatorname{Re}=0.94$, whereas in the control group $\mathrm{Rc}=0.63$. As you can see, in this section the efficiency ratio of the methodology (on the complementarity idea development) used is a3 $=1.49$.

In the course of the research, the authors also conducted two assessments on the special theory of relativity. Here too, with almost identical initial conditions $(\mathrm{Rc}=0.58, \mathrm{Re}$ $=0.62$ ), similar results were obtained after the second assessment: $\mathrm{Rc}=0.69$ in the control group and $\mathrm{Re}=$ 0.90 in the experimental group. The efficiency ratio of the technique used is 1.30 .

Based on the analysis of the above results, inference should be drawn that if the above pedagogical conditions are met, the proposed methodological recommendations for dialectical thinking development in students of technological, physicomathematical and psychological faculties of Russian universities are quite effective, since the acquisition efficiency of natural science disciplines pursuant to their application increases by a factor of 1.31.52.

This conclusion is confirmed by the use of the statistical method - criterion $\chi^{2}$ [24]. Calculations have shown that the numerical value of 'Chi-square' $\left(\chi^{2}\right)$ calculated by Equation 6 is 9.87, which was much higher than the 'Chisquare' critical (3.84) corresponding to the significance level of 0.05 and a single degree of freedom. Hence, the 'null hypothesis' about the possibility to achieve such sufficiently high results in development of integrative concepts and dialectical thinking in students accidentally is discarded; the significant differences between the samples are conditioned by the proposed methodology implementation; the conclusion about its high efficiency is reliable and the set of pedagogical conditions that determine its success is necessary and sufficient.

The use of the integrative method and the complementarity method in the process of elaborating methodological guidelines in the disciplines 'Modern Natural Science Concept' and 'General Physics' as well as the use of the conventional method for instruction organization have contributed to the development of dialectical thinking in students by:

- demonstration of the role of scientific concepts and ideas;

- substantiation of forms and styles of thinking;

- formation of a general worldview and a thinking pattern in students;

- considering and understanding of the general fourstage structure of any concept;

- foundation of the essence of formation of systemic and non-systemic facts;

- generalization of the 'concept' category interpretation;

- selection of styles of dialectical thinking and an optimistic hypothesis about these styles merging in any person 'in the norm';
- focus on distinguishing the actual and prospective styles of thinking;

- classification of subject matters into material and ideal ones;

- determination of the principles of complementarity;

- substantiation of the nature of dialectical thinking essence;

- generalization of the treatment of dialectics.

The experimental and theoretical research carried out has confirmed the effectiveness of using the integrative method and the complementarity method with the aim of developing dialectical thinking in students in the process of studying the courses 'Modern Natural Science Concept' and 'General Physics'. In other words, the hypothesis of improving the quality of education through integrated concepts formation in the framework of ensuring interdisciplinarity in the learning process has been borne out by events. This approach serves as the basis for implementation and achievement of the maximum efficiency of the gnostic approach in the national education system.

\section{CONCLUSIONS}

The empirical investigation results have allowed for the following conclusions:

1. Against the backdrop of a robust relationship between the quality of higher education and economic and social development in the Russian Federation, the national policy should prioritize the intensive way of higher education development (its qualitative component) over the extensive way within the framework of the gnostic approach, guaranteeing the comprehensiveness and systematicity when structuring the content of education.

2. Within the framework of the research, dialectical thinking in students of higher educational institutions was evaluated through the example of the academic disciplines 'Modern Natural Science Concept' and 'General Physics' using conventional methods of instruction organization. The result of the pedagogical experiment have attested to a highly developed statement of students' moral values, their mythological and religious world outlook, but a low level of scientific cognition and residual knowledge. The maximum coefficient of residual knowledge (C) is 0.51 . The data have allowed for the conclusion of the necessity to use the integrative method and the complementarity method when elaborating methodological guidelines for disciplines and the educational process organization as the basis for integrative concepts and formation of integrated thinking in students.

3. The core principles for elaborating methodological support for the academic disciplines 'Modern Natural Science Concept' and 'General Physics' that facilitate and ensure cross-curriculum communica- 
tions in the training process are: elimination of duplication, unambiguity of concepts and unambiguity of interpretations. An important criterion for ensuring cross-curriculum communications is continuity and novelty.

4. Substantiation of the necessity to use special assignments and exercises of reflexive and supplementary type in the organization of instruction has made it possible to formulate and argue the criteria for integrated concepts formedness in students as a factor in dialectical thinking development.

5. Taking into account the complementarity method, the problem-based developmental programmed exercise 'Evolution of the idea of complementarity' has been developed to ensure the integrity of syllabi, their interdisciplinarity, development of professional skills to demonstrate the relationship dialectics of the subjects under study and the dialectics of cognition process in the framework of integrative concepts.

6. The criteria formed for a 'transition' of a student's thinking from the actual one to another level of dialectical thinking developed in them and the use of a scale of correspondence between the values of the coefficients of thoroughness and depth of integrative concepts acquisition and the levels of dialectical thinking development have testified to effectively elaborated methodological support for the disciplines and the organization of instruction using the complementarity method and the integrative method. The efficiency ratio of the guidance papers utilization was a3 $=1.49$. In general, it has been proved that if the above pedagogical conditions are met, the suggested methodological recommendations for dialectical thinking development in students of Russian HEls are quite effective, since the efficiency of acquisition of natural science disciplines as a result of their application increases by 1.3-1.52 times.

7. The proposed practical developments to improve the training process based on the complementarity method and the integrative method will contribute to improving the quality of education in the Russian Federation. In turn, this will ensure effective implementation of the gnostic approach in education as a factor in enhancing intellectualization of modern production, on the one hand, and providing a high level of knowledge - a component in human potential, on the other hand.

\section{REFERENCES}

1. Orekhov, V. (2015). Prognostics: from the past to the future of mankind. MIM LINK, Zhukovsky.

2. OECD. Better Policies for Better Lives. (2017). Education at a Glance 2017: OECD Indicators. OECD Publishing, Paris, DOI: 10.1787/eag-2017en, from http://www.oecd.org/education/education-at-a-glance-19991487.htm, accessed on 201804-28.

3. Drylie, S. (2016). Interpreting Adam Smith's views on the education of the poor in the age of benevolence. George Mason University, Fairfax.

4. Barnard, T. (2010). William Petty and the ambitions of political arithmetic. Irish Studies Review, vol. 18, no. 3, 365-366, DOI: 10.1080/09670882.2010.493029.

5. Espinosa, E. (2016). Systemic knowledge-based assessment of higher education programs. Information Science Reference, Hershey, DOI: 10.4018/978-1-5225-0457-3, from https://books. google.com.ua/books?id=05BJDAAAQBAJ\&p$g=P A 36 \& l p g=P A 36 \& d q=$ theory+of+the+quality+of+knowledge+Edward+Denison\&source=bl\&ots=GIOloVOgyV\&sig=_is5Vj1hUI9bbKQAJob_nVtyk$F Q \& h l=r u \& s a=X \& v e d=0 a h U K E$ wiE6Ze4juPaAhUIDiwKHYEdCRIQ6AEIRDAE\#v=onepage\&q=the ory $\% 20$ of $\% 20$ the $\% 20$ quality $\% 20$ of $\% 20$ knowledge\%20Edward\%20Denison\&f=false, accessed on 2018-04-28.

6. CIPD. (2017). Human capital theory: assessing the evidence for the value and importance of people to organizational success. Chartered Institute of Personnel and Development, London, from https://www. cipd.co.uk/Images/human-capital-theory-assessing-the-evidence_tcm18-22292.pdf, accessed on 2018-04-28.

7. Ginetsinsky, V.I. (1999). The educational standard as a problem of theoretical pedagogy. Pedagogy, no. 8, 12-15.

8. Yelmanova, V.K. (1973). Formation of gnostic abilities in future teachers. Ph.D. Thesis. Leningrad.

9. Kuzmina, N.V. (1975). Levels of pedagogical abilities and problems of social perception. Theoretical and Applied Problems of Psychology of people's cognition of Each Other, no. 4, 72-82.

10. Wilson, B., Cole, P. (1991). A review of cognitive teaching models. Educational Technology Research and Development, vol. 39, no. 4, 47-64, DOI: 10.1007/BF02296571.

11. Huot, J. (1995). Dimensions of Learning. College Quaterly, vol. 2, no. 3, from http://collegequarterly. ca/1995-vol02-num03-spring/huot.html, accessed on 2018-04-28.

12. Gidley, J., Hampson, G., Wheeler, L., Bereded-Samuel, E. (2010). From access to success: an integrated approach to quality higher education informed by 
social inclusion theory and practice. Higher Education Policy, vol. 23, no. 1, 123-147, DOI: 10.1057/ hep.2009.24, from https://www.researchgate.net/ publication/228674646_From_Access_to_Success_An_Integrated_Approach_to_Quality_Higher_ Education_Informed_by_Social_Inclusion_Theory and_Practice?_sg=fhySGFYzm8Y_DcunNöCADcTnjtclCjUfqQYuia7jzZMGhm8ZAQ̄nPg4qikcYwrllTRvB-UrWZuReKrsw, accessed on 2018-04-15.

13. Manatos, M.J., Rosa, M.J., Sarrico, C.S. (2018). Quality management in universities: towards an integrated approach? International Journal of Quality \& Reliability Management, vol. 35, no. 1, 126-144, DOI: 10.1108/IJQRM-04-2016-0046.

14. Makarov, A.B. (2012). The complementarity principle of N. Bohr and the problem of its status. Scientific Yearbook of the Institute of Philosophy and Law of the Ural Division of the Russian Academy of Sciences, no. 12, 98-109, from http://yearbook.uran.ru/en/ archive/49-issue-2012-12/229-complementary-principle-of-n-bohr-and-problem-of-its-status, accessed on 2018-03-27.

15. Semenov, V.A., Dragalov, K.V., Ilyin, D.V., Morozov, S.V., Sidyaka, O.V. (2010). On complementary principles of object-oriented constraint programming. Programming and Computer Software, vol. 36, no. 5, 264-275, DOI: 10.1134/S0361768810050026.

16. Mudrik, A.V. (2000). Social pedagogy. Publishing Center "Academy", Moscow, from https://studfiles. net/preview/6310077/, accessed on 2018-03-29.

17. Ribeiro, F.S., Soares, B.O., Santos, I.F., Da Silva Júnior, E.X. (2017). Neurogame: An alternative and complementary method in the teaching and learning process of neuroanatomy. International Journal of Research \& Methodology in Social Science, vol. 3, no. 1, 62-71, from https://www.researchgate. net/publication/316940133_NEUROGAME_An_Alternative_and_Complementary_Method_in_the Teaching_and_Learning_Process_of_Neuroanatomy?_sg=USxJZuBz24PYG21QssyhAZP5eJh5Eji-wPyqZAtwZw3L4m9M5iZZh4UrRGINfx7VtQApujw2kl7hl20, accessed on 2018-05-03.

18. Ganaeva, E.E. (2015). Principles and methods of teaching, implemented by educational programs of higher education. Education and Upbringing, no. 5, 63-65.

19. Li, N., Chan, D., Mao, Q., Hsu, K., Fu, Zh. (2018). Urban sustainability education: Challenges and pedagogical experiments. Habitat International, no. 71, 70-80, DOI: 10.1016/j.habitatint.2017.11.012, from https://ac.els-cdn.com/ S0197397517305635/1-s2.0-S0197397517305635main.pdf?_tid=814e44a4-372d-4e7a-9b31-cdce8dd9ef06 $\overline{6}$ \&acdnat $=1526655276 \_30$ ea81f9841d637c864bd9a2e60e0d60, accessed on 2018-04-23.
20. Potekhina, N., Shulinina, Yu, Kuzmina, N., Potalisina, L., Sannikova, I. (2016). Correlational-regression analysis application for the forecast of the specialists with higher education requirement in Russian economy. International Journal of Economics and Financial Issues, vol. 6, no. 2, 617-620, from http:// econjournals.com/index.php/ijefi/article/view/1947, accessed on 2018-04-25.

21. Topaj, A., Mirschel, W. (2018). Abnormal shapes of production function: Model interpretations. Computers and Electronics in Agriculture, no. 145, 199-207, DOI: 10.1016/j.compag.2017.12.039.

22. Bethlehem, J., Cobben, F., Schouten, B. (2009). Indicators for the representativeness of survey response. Symposium 2008: Data Collection: Challenges, Achievements and New Directions, from http://www.statcan.gc.ca/pub/11-522-x/2008000/article/10976-eng.pdf, accessed on 2018-04-28.

23. Gavrilin, S.A. (2014). Assessment of the effectiveness of the learning process, from https:// www.google. com/url? sa $=\mathrm{t} \& \mathrm{rct}=\mathrm{j} \& \mathrm{q}=\&$ \& src $=\mathrm{s} \&$ source $=$ web $\& c d=9 \& c a d=r j a \& u a c t=8 \& v e d=0 a-$ hUKEwie6p6m9uPaAhXDkywKHb-_AdoQFghUMAg\&url=http $\% 3 \mathrm{~A} \% 2 \mathrm{~F} \% 2 \mathrm{Fddtna9line.}$ ru $\% 2$ Fwp-content $\% 2$ Fuploads $\% 2$ F2014\%2F02\%2FOzenka_effectivnosti_processa_obuchenija. doc\&usg=AÖvVaw3N1XXyvCNbxwleRhizEfal, accessed on 2018-04-28.

24. Nabiulina, L.M. (2015). Use the criterion $x 2$ (Chisquare) to conduct a statistical analysis of the pedagogical experiment, from https://ipi1.ru/s/196-ispolzovanie-kriteriya-2-khi-kvadrat.html, accessed on 2018-04-30.

25. Bondarenko, N.V., Gokhberg, L.M., Zabaturina, I.Yu. et. al. (2017). Indicators of education: 2017. Higher School of Economics, Moscow, from https://www. hse.ru/primarydata/io2017, accessed on 2018-0428.

26. United Nations Development Programme. (2016). Human Development Report 2016: Human Development for Everyone, from http://hdr.undp.org/ en/2016-report, accessed on 2018-04-28.

27. GDP per capita. (2018). The World Bank Group, from https://data.worldbank.org/indicator/NY.GDP. PCAP.CD, accessed on 2018-04-28.

28. Statistics of Science and Education. (2018). SRI FRCEC, from http://csrs.ru/archive/, accessed on 2018-04-28. 
29. Aydarova, O. (2014). Universal principles transform national priorities: Bologna Process and Russian teacher education. Teaching and Teacher Education, no. 37, 64-75, DOI: 10.1016/j. tate.2013.10.001, from https://www.researchgate. net/publication/259131812_Universal_principles_ transform_national_priorities_Bologna_Process_ and_Russian_teacher_education?_sg=ŠSblCB8w5b44LLpcQLrf4B8XhurxUGYx_ehHXoVHZO2D8_LysERy9qGfKKNNmAY8rlhzIFyrfhYzloLQ, accessed on 2018-04-27.

30. Fedotova, O. (2015). Russian education in the system of global interactions: Trends and theoretical projection. Procedia - Social and Behavioral Sciences, no. 214, 414-421, DOI: 10.1016/j.sbspro.2015.11.695, from https://www.researchgate. net/publication/287159620_Russian_Education_in_ the_System_of_Global_Interactions_Trends_and_ Theoretical_Projection?ev=publicSearchHeader\& sg=rlhHOldV̄U5AiDRKFEi98ncLgz5hgMnUT7NPHgC8Q_EQrU8yrNk-q8hl4Oiu8M6VWc5sMI0jFzpJHunA, accessed on 2018-02-19.

31. Granatov, G.G. (2000). The method of complementarity in the development of concepts (pedagogy and psychology of thinking). Magnitogorsk State University Press, Magnitogorsk.

32. Educational portal of Nosov MSTU. (2018). Curricula (bachelor degree course program 2017), from http:// newlms.magtu.ru/mod/data/view.php?d=99\&advanced=0\&paging\&page=8, accessed on 2018-0420.

33. Official website of the Nosov Magnitogorsk State Technical University, from http://magtu.ru/, accessed on 2018-04-28.

34. Itkulova, L.A. (2015). Worldview as a socio-cultural phenomenon. Theory and Practice of Social Development, no. 21, 209-211, from http://teoria-practica. ru/rus/files/arhiv_zhurnala/2015/21/philosophy/itkulova.pdf, accessed on 2018-03-19.
35. Steel, D., Gonnerman, Ch., O'Rourke, M. (2017). Scientists' attitudes on science and values: Case studies and survey methods in philosophy of science. Studies in History and Philosophy of Science, no. 63, 22-30, DOI: 10.1016/j.shpsa.2017.04.002.

36. Sergeeva, L.A. (2010). The modern physical picture of the world: the philosophical aspect, from https://www.pglu.ru/upload/iblock/608/uch_2010_ xiv_00042.pdf, accessed on 2018-04-28.

37. Dvorak, I., Ciharova, K., Kosova, H., Valach, J. (2015). Innovative approaches to education in natural sciences at the Charles University in Prague. Procedia - Social and Behavioral Sciences, no. 176, 546-551, DOI: 10.1016/j.sbspro.2015.01.509, from https://www. researchgate.net/publication/276859375_Innovative_Approaches_to_Education_in_Natural_Sciences_at_the_Charles_University_in_Prague? sg= qJn'LhIDWaLKGKX-fuPVs7vWoxL-4Dyy1364jmHUfLQC2gP0ipVOlxrtdCan1RTni04mhS_PuWa9vBM, accessed on 2018-03-24.

38. Usova, A.V. (2016). Formation of learning and cognitive skills in the study of natural cycle subjects, from http://Fiz.1 september.ru/article.php?ID=200601602, accessed on 2018-04-28.

39. Tulkibaeva, N.N. (1997). The main directions for the implementation of developmental education in Russian schools. Theory and practice of developmental learning. Publishing House "Fakel", Chelyabinsk.

40. Bespalko, V.P. (1997). Basics of the theory of pedagogical systems (problems and methods of psychological and pedagogical support for practical learning systems). Voronezh State University, Voronezh. 